Pesq. Vet. Bras. 24(3):115-119, jul./set. 2004

\title{
Uso da ciclofosfamida em modelo de imunodepressão experimental em ovinos ${ }^{1}$
}

\author{
Maurício Garcia², Silvio P. Sertório², Glaucie J. Alves², Sabrina C. Chate², Roberta \\ Carneiro ${ }^{2}$ e Maria A. Lallo ${ }^{2}$
}

\begin{abstract}
Garcia M., Sertório S. P., Alves G. J., ChateS. C., Carneiro S. \& Lallo M.A. 2004. [Ovine experimental immunosuppression using cyclophosphamide.] Uso da ciclofosfamida em modelo experimental de imunodepressão experimental em ovinos. Pesquisa Veterinária Brasileira 24(3): 115-119. Curso de Medicina Veterinária, Universidade Paulista, Rua Enjolras Vampré 146, São Paulo, SP 04290-070, Brazil. E-mail: mgar@ mgar.vet.br

Cyclophosphamide (CY) was used to evaluate the effect on the immune system of sheep. Castred adult rams were divided into 3 groups, with 6 animals each one. Group I (day 0) and Group II (day 1) were treated with $\mathrm{CY}(40 \mathrm{mg} / \mathrm{kg}$, single dose, IV), and Group III was not treated and remained as control. All groups were immunized on day 0 with B19 brucellosis vaccine. On day 6 , all animals were bled and serum agglutination test for brucellosis antibodies detection was performed. During 7 days blood lymphocyte counts and electrophoresis gammaglobulin dosage were daily performed. The results showed statistical decrease of immune response. Low serum titers of brucellosis antibodies were found in Groups I and II, and Iymphopenia and hypogammaglobulinemia were also found in these groups. A high mortality rate $(40 \%$ occurred in the treated animals.
\end{abstract}

INDEX TERMS: Immunosupression, cyclophosfamide, immunology, sheep.

RESUM 0.- A ciclofosfamida (CY) foi usada para avaliar o efeito no sistema imune de ovinos. Carneiros adultos castrados foram divididos em 3 grupos, com 6 animais cada. Os GruposI (dia 0 ) ell (dia 1) foram tratados com a CY (40 mg/kg, dose única, IV), e o Grupo III não foi tratado, permanecendo como controle. Todos os grupos foram imunizados no dia 0 com a vacina B19 contra a brucelose. No dia 6 , todos animais foram sangradose foi realizado o teste de soro-aglutinação para detecção de anticorpos anti-brucella. Foram também realizadas, diariamente durante 7 dias, contagens de linfócitos sangüíneos e dosagens de gamaglobulinas séricas por eletroforese. Os resultados encontrados mostraram uma diminuição estatística da resposta imune. Foram encontrados, nos Grupos I e ll, baixos títulos de anticorpos anti-brucella, além de linfopenia e hipogamaglobulinemia. Uma alta mortalidade $(40 \%$ foi encontrada nos animais tratados.

TERMOS DE INDEXAÇÃO: Imunodepressão, ciclofosfamida, imunologia, ovinos.

${ }^{1}$ Recebido em 9 de novembro de 2001.

Aceito para publicação em 14 de maio de 2003.

Trabalho realizado com suporte financeiro da FAPESP, Proc. no 99/10980-3.

${ }^{2}$ Curso de Medicina Veterinária, Universidade Paulista, Rua Enjolras Vampré 146, São Paulo, SP 04290-070. E-mail: mgar@ mgar.vet.br

\section{INTRODUÇÃO}

As mudanças recentes na pecuária brasileira e mundial apontam para um novo paradigma de criação, em que o uso de defensivos animais é limitado ao mínimo indispensável, senão completamente abolido, no sentido de serem produzidos alimentos, tanto carne quanto leite, isentos de quaisquer resíduos químicos. A palavra de ordem hoje é a prevenção e manutenção de animais sadios para que possam utilizar as suas próprias defesas para o combate das diversas enfermidades que são comuns em rebanhos submetidos a manejos intensivos.

0 estudo do sistema imune dos ruminantes desempenha, assim, um papel chave neste cenário. Dentro deste contexto, os modelos experimentais de imunodepressão apresentam-se como uma valiosa ferramenta para avaliar o comportamento do sistema imune. 0 estabelecimento detais modelos, bem documentados e com boa reprodutibilidade, permite a realização de inúmeros experimentos, tais como a avaliação do efeito de imunomoduladores e o desenvolvimento de novas técnicas de mensuração da resposta imune.

Diversas drogas têm sido empregadas em modelos de imunodepressão em várias espécies, como a dexametasona, a ciclosporina, a ciclofosfamida e o metotrexato. Todavia, o efeito destas drogas não é o mesmo em todas as espécies. 0 metotrexato, por exemplo, é capaz de inibir a resposta imune 
em camundongos tratados com 2,5 mg/kg em dose única (Romanycheva et al. 1978). Entretanto, Greenwood \& Keny (1978) não conseguiram provocar alterações hematológicas em ovinos tratados durante 3 dias com $5 \mathrm{mg} / \mathrm{kg}$ de metotrexato.

Em camundongos, Doherty (1981) mostrou que a ciclofosfamida inibe a produção de anticorpos, mas não conseguiu demonstrar o efeito da droga na resposta celular cutânea. Já Tarayre et al. (1990) encontraram leucopenia em camundongos tratados com essa droga.

Outro exemplo desta diversidade de efeito éa dexametasona, um potente glicocorticóide usado em diversos modelos de imunodepressão. Tal efeito foi bem documentado em várias espécies, como bovinos (Roth \& Kaerbele 1985, Pruett et al. 1987, Doherty et al. 1995), ratos (Wira et al. 1990, Bakker et al. 1997)e até gal inhas (Isobe \& Lillehoj 1993). Todavia, Saulnier et al. (1991) falharam ao tentar demonstrar o efeito imunodepressor da dexametasona em suínos e Minton \& Blecha (1991) e Garcia et al. (1999) também não conseguiram encontrar tal efeito em ovinos.

Esses resultados ressaltam a necessidade de serem desenvolvidos modelos próprios para cada espécie, já que as conclusões obtidas em uma espécie não podem necessariamente ser extrapolada para outra.

A cicl ofosfamida é uma mostarda nitrogenada que tem sido usada no tratamento de diversos tipos de câncer. A droga é um potente imunodepressor, atuando em células com alta atividade mitótica, inibindo tanto a resposta imune humoral quanto celuIar (Bach \& Strom 1986).

Um dos efeitos colaterais da ciclofosfamida, a queda de cabelos, chamou a atenção de alguns pesquisadores para a possibilidade do uso da droga para facilitar a tosquia em ovinos. Logo, surgiram várias publicações sobre a chamada "tosquia química" com a ciclofosfamida, como citado em Homan et al. (1969) e Dolnick et al. (1969). Nestes animais, a lã pode ser completamente removida com a mão ao redor do $10^{\circ}$ dia após a aplicação da droga.

O uso da ciclofosfamida em ovinos levou pesquisadores como Bakke et al. (1972) e Schaumloffel et al. (1973) a estudar o seu metabolismo nesta espécie. Além destes pesquisadores, muitos outros se dedicaram ao tema e vários aspectos foram descritos, como 0 efeito no bulbo folicular da lã, na atividade testicular, na gestação, na atividade da acetilcolinesterase, no crescimento da lã e nas infecções micóticas (Dolnick et al. 1970, Mclntosh et al. 1971, Jackson et al. 1975).

Apesar desta grande variedade de trabalhos, são poucos os estudos específicos sobre o efeito da cicl ofosfamida no sistema imune de ovinos. Prasad et al. (1986) estudaram o efeito da droga na resposta à vacinação contra o ectima contagioso. Bogdanov \& Kusnedelcheva (1977) encontraram hipogamaglobulinemia em ovelhas adultas tratadas com ciclofosfamida. Jun \& Johnson (1979) relataram o efeito imunosupressor da droga em ovinos com carcinoma induzido experimentalmente. Yegana et al. (1983) não conseguiram evidenciar significativas alterações leucocitária ou na fração de gamaglobulina após a aplicação da cicl ofosfamida em ovinos.

Diversos protocolos para o uso da ciclofosfamida em ovinos têm sido propostos, com diferentes propósitos, com doses variando de 10 a $50 \mathrm{mg} / \mathrm{kg}$, tanto via oral quanto intravenosa (Dolnick et al. 1969, Mclntosh et al. 1971, Bakke et al. 1972, Jackson et al. 1975, Bogdanov \& Kusnedelcheva 1977, Gordon 1982, Yegana et al. 1983, Prasad et al. 1986).

0 objetivo do presente trabalho foi avaliar o efeito da ciclofosfamida em um modelo de imunodepressão em ovinos, através da titulação de anticorpos anti-brucella, pós-vacinais, e também pela contagem de linfócitos sangüíneos e pela dosagem de gamaglobulinas séricas.

\section{MATERIAL E MÉTODOS}

Foram utilizados 18 ovinos sem raça definida, machos adultos e castrados, com pesos ao redor de $35 \mathrm{~kg}$. Os animais foram mantidos em baias com cama de serragem e alimentados com feno de alfafa.

Foram constituídos 3 grupos experimentais, com 6 animais cada grupo. Os animais dos Grupos I e II receberam $40 \mathrm{mg} / \mathrm{kg}$ de ciclofosfamida (Genuxal ${ }^{\circledR}$, Asta Médica) por via intravenosa e os animais do Grupo III permaneceram como controle.

Pretendeu-se avaliar a capacidade dos animais em produzir anticorpos específicos após a aplicação de determinado antígeno. Para tanto, foi utilizada a vacina contra a brucelose bovina como antígeno. Assim, todos os animais foram imunizados com $2 \mathrm{ml}$ de vacina contra a brucelose, amostra B19 (Aborvac ${ }^{\circledR}$, Fort Dodge), por via subcutânea. Seis dias após a vacinação, foi feita a titulação de anticorpos anti-brucella, através da soro-aglutinação rápida em placa. A técnica empregada é uma variante da técnica tradicional descrita por Huddleson \& Abel em 1928 e foi padronizada por Garcia et al. (2000). 0 soro foi previamente diluído com solução salina $(0,9 \% \mathrm{NaCl})$, de acordo com as seguintes concentrações: 1:1, 1:5, 1:10, 1:20, 1:30,

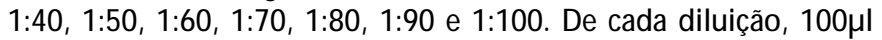
foram misturados com $50 \mu \mathrm{l}$ de um antígeno comercial para diagnóstico da brucelose bovina (Instituto Butantan) sobre uma placa de vidro. A mistura foi suavemente homogeneizada e, após 8 minutos, foi avaliada a aglutinação. 0 título foi 0 correspondente à maior diluição que apresentou reação com aglutinação positiva.

Para se avaliar o melhor momento para a aplicação da ciclofosfamida, com relação ao momento da imunização anti-bruclla, os animais do grupo I foram imunizados no mesmo dia em que foram tratados com a ciclofosfamida e os animais do grupo II foram imunizados 24 horas após.

Como elementos adicionais para a avaliação do sistema imune, foi feita a contagem de linfócitos sangüíneos em câmara hematimétrica e extensões sangüíneas (Hewitt 1984) e a dosagem de gamaglobulinas séricas, por eletroforese (Barta \& Pourciau 1984). Tais avaliações foram feitas diariamente, durante uma semana após a aplicação da ciclofosfamida.

Os dados foram analisados estatisticamente por análise de variância (Zar 1996), para um valor de $p=5 \%$ Foi empregada planilha eletrônica comercial (Excel $97 \AA$, Microsoft) de acordo com as recomendações de Dretzke \& Heilman (1998).

\section{RESULTADOS}

Os resultados da titulação de anticorpos vacinais anti-brucella mostraram haver uma diminuição estatisticamente significante nos animais dos grupos I (média $=1,4$ ) e II ( édia $=11,5$ ), com relação ao grupo controle (média = 37,5). Notou-se, ainda, que a média do grupo I foi menor que a encontrada no grupo II, mostrando que a aplicação simultânea da ciclofosfamida no momento da imunização provoca uma imunodepressão mais intensa do que aquela obtida com a apli- 
cação da ciclofosfamida um dia antes da imunização (Quadro 1, Fig. 1).

Nos animais tratados com ciclofosfamida, encontrou-se uma intensa linfopenia (Quadro 2, Fig. 2). A linfopenia já pode ser detectada 24 horas após a aplicação da droga, atingindo seu patamar mais baixo ao redor do $4^{\circ}$ e $5^{\circ}$ dia, iniciando, então, uma lenta recuperação.

Com relação aos valores da gamaglobulina, os resultados foram mais discretos, mas ainda estatisticamente significantes.

Quadro 1. Títulos de anticorpos vacinais anti-brucella em ovinos tratados com ciclofosfamida no dia 0 (Grupo I), no dia -1 (Grupo II) e sem tratamento (Grupo III)

\begin{tabular}{|c|c|c|c|c|c|c|c|c|}
\hline \multicolumn{3}{|c|}{ Grupo I } & \multicolumn{3}{|c|}{ Grupo II } & \multicolumn{3}{|c|}{ Grupo III } \\
\hline Anima & Dia 0 & Dia 6 & Animal & Dia 0 & Dia 6 & Animal & Dia 0 & Dia 6 \\
\hline $355+$ & 0 & 0 & 354 & 0 & 1 & 351 & 0 & 60 \\
\hline 358 & 0 & 1 & 356 & 0 & 30 & 357 & 0 & 30 \\
\hline $359+$ & 0 & 0 & $362+$ & 0 & $\ldots$ & 365 & 0 & 30 \\
\hline $360+$ & 0 & $\ldots$ & $363+$ & 0 & $\ldots$ & 366 & 0 & 5 \\
\hline 361 & 0 & 1 & 364 & 0 & 10 & 367 & 0 & 40 \\
\hline 371 & 0 & 5 & 368 & 0 & 5 & 369 & 0 & 60 \\
\hline Média & 0 & $1,4^{\mathrm{a}}$ & Média & 0 & $11,5^{\mathrm{a}}$ & Média & 0 & 37,5 \\
\hline
\end{tabular}

a Médias estatisticamente menores com relação ao grupo controle (III). + Animais que morreram.

Quadro 2. Valores de linfócitos sangüíneos (em céls./ $\mu$ l) de ovinos tratados com ciclofosfamida no dia 0 (Grupo I), no dia -1 (Grupo II) e sem tratamento (Grupo III)

\begin{tabular}{|c|c|c|c|c|c|c|c|c|c|}
\hline \multicolumn{10}{|l|}{ Grupo I } \\
\hline Animal & Dia -1 & Dia 0 & Dia 1 & ia 2 & Dia 3 & ia 4 & Dia 5 & Dia 6 & Dia \\
\hline $\begin{array}{c}355 t \\
358 \\
359 \dagger \\
360 t \\
361 \\
371 \\
\text { Média }\end{array}$ & $\begin{array}{l}4368 \\
2150 \\
2124 \\
3705 \\
3930 \\
4457 \\
3456\end{array}$ & $\begin{array}{l}4860 \\
2364 \\
2219 \\
2822 \\
3540 \\
4325 \\
3355\end{array}$ & $\begin{array}{c}1134 \\
1691 \\
644 \\
451 \\
595 \\
1533 \\
1008^{a}\end{array}$ & $\begin{array}{c}41 / \\
1029 \\
1860 \\
804^{a}\end{array}$ & $\begin{array}{c}1748 \\
618 \\
468 \\
308 \\
176 \\
742 \\
677^{a}\end{array}$ & $\begin{array}{c}1118 \\
342 \\
315 \\
759 \\
683 \\
651^{a}\end{array}$ & $\begin{array}{c}419 \\
400 \\
216 \\
392 \\
499 \\
789 \\
452^{a}\end{array}$ & $\begin{array}{l}1018 \\
716^{a}\end{array}$ & $\begin{array}{l}348 \\
777 \\
641^{a}\end{array}$ \\
\hline \multicolumn{10}{|l|}{ Grupo II } \\
\hline Animal & Dia -1 & Dia 0 & Dia 1 & Dia 2 & Dia 3 & Dia 4 & Dia 5 & Dia 6 & Dia 7 \\
\hline $\begin{array}{c}354 \\
356 \\
362 \dagger \\
363 \dagger \\
364 \\
368 \\
\text { Média }\end{array}$ & $\begin{array}{l}2365 \\
2063 \\
3851 \\
3034 \\
2535 \\
3420 \\
2878\end{array}$ & $\begin{array}{c}1862 \\
1416 \\
1700 \\
2979 \\
2342 \\
828 \\
1854\end{array}$ & $\begin{array}{c}1960 \\
355 \\
1290 \\
1731 \\
1485 \\
868 \\
1281^{a}\end{array}$ & $\begin{array}{c}899 \\
717 \\
1374 \\
370 \\
1063 \\
994 \\
903^{a}\end{array}$ & $\begin{array}{c}527 \\
1055 \\
598 \\
956 \\
555 \\
503 \\
699^{a}\end{array}$ & $\begin{array}{c}625 \\
536 \\
688^{a}\end{array}$ & $\begin{array}{c}880 \\
1240 \\
\ldots\end{array}$ & $\begin{array}{c}1307 \\
1111 \\
\ldots\end{array}$ & $\begin{array}{c}1160 \\
511 \\
897^{a}\end{array}$ \\
\hline
\end{tabular}

\begin{tabular}{cccccccccc}
\multicolumn{2}{l}{ Grupo III } \\
\hline Animal & Dia -1 & Dia 0 & Dia 1 & Dia 2 & Dia 3 & Dia 4 & Dia 5 & Dia 6 & Dia 7 \\
\hline 351 & 2066 & 2066 & 1812 & 3218 & 1634 & 2070 & 2489 & 2027 & 1288 \\
357 & 2436 & 1838 & 1449 & 2525 & 1651 & 1300 & 2865 & 1733 & 2365 \\
365 & 4520 & 2139 & 3965 & 4523 & 1876 & 2683 & 2490 & 3159 & 2606 \\
366 & 2436 & 5256 & 4179 & 4154 & 2726 & 2504 & 3268 & 2581 & 1863 \\
367 & 1782 & 2465 & 2149 & 2898 & 1430 & 1431 & 1244 & 1820 & 1782 \\
369 & 3891 & 4740 & 3379 & 4079 & 2820 & 2882 & 3039 & 3597 & 4201 \\
Média & 2855 & 3084 & 2822 & 3566 & 2023 & 2145 & 2566 & 2486 & 2351
\end{tabular}

a Médias estatisticamente menores com relação ao grupo controle (III). + Animais que morreram.

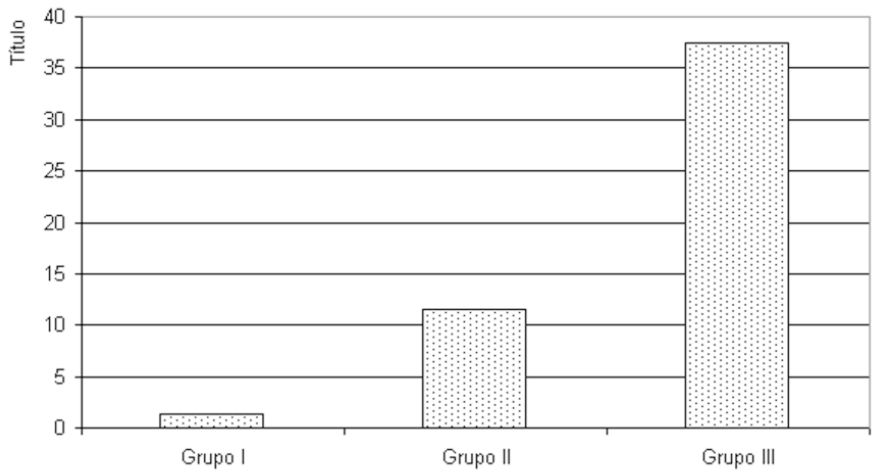

Fig. 1. Títulos de anticorpos vacinais anti-brucella em ovinos tratados com ciclofosfamida no dia 0 (Grupo I), no dia -1 (Grupo II) e sem tratamento (Grupo III).

Quadro 3. Valores da gamaglobulina sérica (em $\mathrm{mg} / \mathrm{dl}$ ) de ovinos tratados com ciclofosfamida no dia 0 (Grupo I), no dia -1 (Grupo II) e sem tratamento (Grupo III)

\begin{tabular}{|c|c|c|c|c|c|c|c|c|c|}
\hline \multicolumn{10}{|l|}{ Grupo I } \\
\hline Animal & Dia -1 & Dia 0 & ia 1 & ia 2 & Dia 3 & Dia 4 & Dia 5 & Dia 6 & Dia \\
\hline 35 & & & 2,0 & & & 1,3 & 16 & 1 & 1,20 \\
\hline & & & 1, & 1, & & 1, & 1,14 & 4 & \\
\hline & 1 & 1,4 & 1,2 & 1,24 & 1, & 1,43 & 1,52 & 1,56 & 1, \\
\hline & 1,5 & 1,40 & 1,7 & 1,23 & 1,50 & 1,65 & 1,70 & & \\
\hline & & 1,7 & 1, & & & 1,55 & 1,69 & 1,51 & 1, \\
\hline & & & & 1, & 1, & 1,44 & 1,31 & 1,45 & 1,23 \\
\hline & 1.55 & 1,5 & 1, & 1. & 1,3 & $1,45^{a}$ & 1,42 & 1,32 & 1,24 \\
\hline
\end{tabular}

\begin{tabular}{cccccccccc}
\multicolumn{10}{l}{ Grupo II } \\
\hline Animal & Dia -1 & Dia 0 & Dia 1 & Dia 2 & Dia 3 & Dia 4 & Dia 5 & Dia 6 & Dia 7 \\
\hline 354 & 1,64 & 1,37 & 1,86 & 1,40 & 1,29 & 1,56 & 1,29 & 1,24 & 1,42 \\
356 & 1,49 & 1,79 & 1,57 & 1,14 & 0,93 & 1,16 & 1,09 & 1,03 & 1,24 \\
$362=\dagger$ & 1,55 & 1,96 & 1,16 & 1,06 & 1,11 & $\ldots$ & $\ldots$ & $\ldots$ & $\ldots$ \\
$363=\dagger$ & 1,50 & 1,21 & 1,48 & 1,30 & 1,20 & $\ldots$ & $\ldots$ & $\ldots$ & $\ldots$ \\
364 & 1,39 & 1,40 & 1,44 & 1,66 & 1,21 & 1,37 & 1,24 & 1,24 & 1,10 \\
368 & 1,51 & 1,88 & 1,29 & 1,47 & 1,20 & 1,38 & 1,42 & 1,29 & 1,16 \\
Média & 1,52 & 1,60 & 1,47 & 1,34 & 1,16 a & 1,37 a & 1,26 & 1,20 & 1,23
\end{tabular}

Grupo III

\begin{tabular}{cccccccccc}
\hline Animal & Dia -1 & Dia 0 & Dia 1 & Dia 2 & Dia 3 & Dia 4 & Dia 5 & Dia 6 & Dia 7 \\
\hline 351 & 1,66 & 1,62 & 1,72 & 1,99 & 2,03 & 2,10 & 1,70 & 1,61 & 1,72 \\
357 & 1,88 & 1,92 & 1,80 & 1,46 & 1,71 & 2,04 & 1,74 & 1,78 & 1,89 \\
365 & 1,35 & 1,14 & 1,43 & 1,08 & 1,24 & 1,57 & 1,37 & 1,21 & 1,13 \\
366 & 2,33 & 2,00 & 1,93 & 1,62 & 1,81 & 2,16 & 1,97 & 1,73 & 1,68 \\
367 & 1,11 & 1,11 & 1,34 & 1,81 & 1,05 & 1,23 & 1,33 & 1,04 & 1,00 \\
369 & 1,39 & 1,51 & 1,32 & 1,36 & 1,78 & 1,72 & 1,59 & 1,50 & 1,33 \\
Média & 1,62 & 1,55 & 1,59 & 1,55 & 1,60 & 1,80 & 1,62 & 1,48 & 1,46
\end{tabular}

a Médias estatisticamente menores com relação ao grupo controle (III). t Animais que morreram.

Conforme exposto no Quadro 3 e na Fig. 3, notou-se uma hipogamaglobulinemia nos animais dos Grupos I e II. A hipogamaglobulinemia torna-se evidente ao redor do 2 dia após a aplicação da droga, atingindo seu patamar mais baixo ao redor do 4을 (Quadro 3, Fig. 3).

Os animais tratados com ciclofosfamida apresentaram queda de lã que se iniciou ao redor do 3 o dia após a aplicação da droga e, ao redor do $10^{\circ}$ dia, já podia ser encontrada a queda 


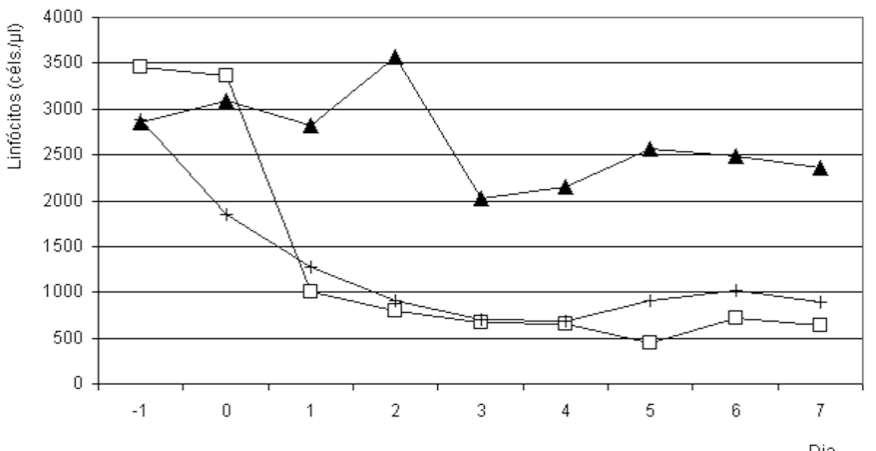

Fig. 2. Valores de linfócitos sangüíneos de ovinos tratados com ciclofosfamida no dia 0 (Grupo I= $\square$ ), no dia -1 (Grupo II= + ) e sem tratamento (Grupo III $\boldsymbol{\wedge}$ ).

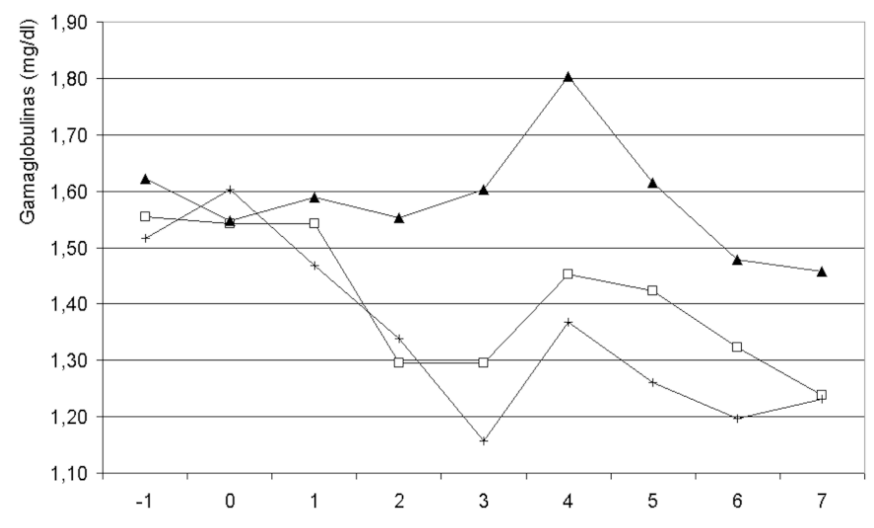

Fig. 3. Valores da gamaglobulina sérica de ovinos tratados com ciclofosfamida no dia 0 (Grupo I= $\square$ ), no dia -1 (Grupo II= + ) e sem tratamento (Grupo $\| I=\mathbf{\Delta}$ ).

total da lã (Fig. 4). Dos 12 animais inoculados, cinco morreram, perfazendo uma mortalidade de $40 \%$ Das cinco mortes, três ocorreram na primeira semana após a aplicação da droga e duas mais tardiamente. Os animais apresentaram lesões degenerativas no fígado e rim.

\section{DISCUSSÃO}

Os experimentos com imunologia aplicada à clínica dependem substancialmente do desenvolvimento de modelos de boa reprodutibilidade. 0 que parece simples à primeira vista, muitas vezes se revela complexo no momento da execução. Por outro lado, modelos considerados bons para uma determinada espécie nem sempre se aplicam a outra. Em experimento anterior, Garcia et al. (1999) não conseguiram provocar imunodepressão em ovinos com a dexametasona, resultado semelhante ao encontrado por Minton \& Blecha (1991), apesar de diversos autores terem obtido sucesso em provocar a imunodepressão com a mesma droga em outras espécies (Roth \& Kaerbele 1985, Pruett et al. 1987, Wira et al. 1990, Isobe \& Lillehoj 1993, Doherty et al. 1995, Bakker et al. 1997). Assim, a principal motivação deste experimento foi a de avaliar o efeito de outra droga, a ciclofosfamida, em modelo de imunodepressão em ovinos.
Os resultados encontrados mostraram claramente 0 efeito imunodepressor da ciclofosfamida. Os animais do grupo controle apresentaram aglutinação de seu soro frente ao antígeno brucélico mesmo quando seu soro era previamente diluído, em alguns casos, até 60 vezes. Já alguns animais inoculados não apresentavam tal aglutinação, mesmo com o soro puro, sem diluição. Resultado semelhante foi encontrado por Prasad et al. (1986), que encontraram forte imunodepressão em animais imunizados contra o ectima contagioso, após serem tratados com a ciclofosfamida.

A linfopenia e a hipogamaglobulinemia encontrada nos animais inoculados reforçaram também esse efeito imunodepressor. Cabe ressaltar, porém, que a linfopenia foi um resultado mais expressivo que a hipogamaglobulinemia. Esse achado semelhante ao relatado por Silva (2000), parece sinalizar que a dosagem de gamaglobulinas não é um indicador tão seguro de imunodepressão; ao menos não parece ser muito sensível.

A escolha da ciclofosfamida baseou-se na indicação pré-existente na literatura (Bogdanov \& Kusnedelcheva 1977, Jun \& Johnson 1979, Yegana et al. 1983, Prasad et al. 1986) e na facilidade de aquisição no mercado a um custo razoavel mente acessível (Genuxal ® , Asta Médica). A escolha da dose de $40 \mathrm{mg} / \mathrm{kg}$ também se baseou na literatura, que indica doses de 10 a $50 \mathrm{mg} /$ $\mathrm{kg}$ (Quadro 1). Entretanto, observou-se uma alta mortalidade nos animais inoculados ( $40 \%$, fato que indica a necessidade de reconsideração dessa dose em experimentos dessa natureza. Portanto, seria conveniente retestar a ciclofosfamida com uma dose menor para verificar se é possível repetir o efeito imunodepressor observado neste trabalho, todavia, com uma provável redução significativa da mortalidade.

\section{CONCLUSÕES}

Com base nos resultados obtidos concluimos que a ciclofosfamida pode ser usada em modelo de imunodepressão em ovinos, poisé capaz de causar diminuição na produção de anticorpos vacinais, linfopenia e hipogamaglobulinemia. Por outro lado, 0 efeito da diminuição de anticorpos vacinais ocorre de maneira mais intensa quando a droga é aplicada no mesmo momento da imunização, em comparação ao efeito obtido quando da aplicação um dia antes. Na dose de $40 \mathrm{mg} / \mathrm{kg}$, usada neste experimento, a ciclofosfamida mostrou-se relativamente tóxica, causando mortalidade de $40 \%$ dos animais inoculados.

\section{REFERÊNCIAS}

Bach J.F. \& Strom T. 1986. The Mode of Action of Immunosuppressive Agents. Elsevier, Amsterdam.

Bakke J.E., Feil V.J., Fjelstul C.E. \& Thacker E.J. 1972. Metabolism of cyclophosphamide by sheep. J. Agr. Food Chem. 20(2):384-388.

Bakker J.M., Schmidt E.D., Kroes H., Kavelaars A., Heijnen C.J., Tilders F.J. \& Van Rees E.P. 1997. Effects of neonatal dexamethasone treatment on hypothalamo-pituitary adrenal axis and immune system of the rat. J. Neuroimmun. 74(1-2):69-76.

Barta O. \& Pourciau S.S. 1984. Electrophoresis, p.116-122. In: Barta 0. (ed.) Laboratory Techniques of Veterinary Clinical Immunology. Charles C. Thomas, Illinois.

Bogdanov M. \& Kusnedelcheva S. 1977. Chemical and hematologic studies of sheep before and after treatment with cyclophosphamide. Vet. Med. 
Nauki. 14(5):87-91. Doherty N.S. 1981. Selective effects of immunosupressive agents against the delayed hypersensitivity response and humoral response to sheep red blood cells in mice. Agents Actions 11:237-242.

Doherty N.S. 1981. Selective effects of immunosupressive agents against the delayed hypersensitivity response and humoral response to sheep red blood cells in mice. Agents Actions 11:237-242.

Doherty M.L., Bassett H.F., Quinn P.J., Davis W.C. \& Monaghan M.L. 1995. Effects of dexamethasone on cell-mediated immune responses in cattle sensitized to Mycobacterium bovis. Am. J. Vet. Res. 56(10):1300-1306.

Dolnick E.H., Lindahl I.L., Terrill C.E. \& Reynolds P.J. 1969. Cyclophosphamide as a chemical "defleecing" agent for sheep. Nature 221(179):467468.

Dolnick E.H., Lindhal I.L. \& Terrill C.E. 1970. Treatment of pregnant ewes with cyclophosphamide. J. Anim. Sci. 31(5):944-946.

Dretzke B.J. \& Heilman K.A. 1998. Statistics with Microsoft ${ }^{\circledR}$ Excel. Practice Hall, New Jersey. 164p.

Garcia M., Kitamura S.S., Rabello P.A., Faria Jr S.P.F., Della Libera A.M.M.P., Silva M.M., Bastos P.A.S., Ramos M.C.C. \& Carvalho V.M. 1999. Modelo experimental para avaliação da resposta imune em ovinos. Revta Inst. Ciênc. Saúde Univ. Paulista 17(1):19-26.

Garcia M., Bertagnon H.G., Sertório S.P. \& Alves G.J. 2000. Titulação de anticorpos anti-Brucella abortus em ovinos experimentalmente imunizados. Anais XXVII Congr. Bras. Med. Veterinária, Águas de Lindóia, SP, p.70.

Gordon A.J. 1982. Effect of dexamethasone and cyclophosphamide on urinary hydroxyproline to creatinine ratios in sheep. Aust. J. Biol. Sci. 35(2):153-161.

Greenwood B. \& Kerry P.J. 1978. The effects of methotrexate and melphalan in sheep. Brit. J. Pharmacol. 63:283-285.

Hewitt S.G. 1984. Haematology, p. 72-100. In: Gray D.E. Manual of Veterinary Investigation, Laboratory Techniques. Vol. 2. 3rd ed. Her Majesty's Stationery Office, London.

Homan E.R., Zendzian R.P., Busey W.M. \& Rall D.P. 1969. Loss of hair in experimental animals induced by cyclophosphamide. Nature 15(221):1058-1059.

Huddleson I.F. \& Abeal F. 1928. Rapid macroscopic agglutination for the serum diagnosis of Bang's abortion disease. J. Infec.Diseases 42:242-7.

Isobe T. \& Lillehoj H.S. 1993. Dexamethasone suppress T cell-mediated immunity and enhances disease susceptibility to Eimeria mivati infection. Vet. Immun. Immunopath. 39(4):431-446.

Jackson C.J., Reynolds P.J. \& Lindhal I.L. 1975. Effect of cyclophosphamide on erythrocyte and plasma acetycholinesterase activity in sheep. J. Anim. Science 41(5):1390-1393.

Jun M.H. \& Johnson R.H. 1979. Effect of cyclophosphamide on tumour growth and cell- mediated immunity in sheep with ovine squamous cell carcinoma. Res. Vet. Sci. 27(2):155-60.

Mcintosh G.H., Smith G.W. \& Cunningham R.B. 1971. Cyclophosphamide in the treatment of mycotic dermatitis of sheep. Aust. Vet. J. 47:542546.

Minton J.E. \& Blecha F. 1991. Cell-mediated immune function in lambs chronically treated with dexamethasone. J. Anim. Sci. 69:3225-3229.

Prasad G., Garg S.K. \& Singh I.P. 1986. Effect of cyclophosphamide on immune response of sheep against attenuated sheep pox virus. Indian J. Exp. Biol. 24(11):692-695.

Pruett J.H., Fisher W.F., Deloach J.R. 1987. Effects of dexamethasone on selected parameters of bovine immune system. Vet. Res. Commun. 11:305-323.

Romanycheva V., Babichev V.A., Uteshev B.S. \& Kalinkovich A.G. 1978. The kinetics of inhibition with methotrexate and vincristine of the primary immune response to sheep red blood cells in mice. Folia Biol. 24:34354.

Roth J.A. \& Kaeberle M.L. 1985. Enhancement of lymphocyte blastogenesis and neutrophil function by avridine in dexamethasone-treated and nontreated cattle. Am. J. Vet. Res. 46(1):53-57.

Saulnier D., Martinod S. \& Charley B. 1991. Immunomodulatory effects of in vivo of recombinant porcine interferon gamma on leukocyte functions of immunosuppressed pigs. Annales de Recherche Vétérinaires 22(1):1-9.

Schaumloffel E., Habermehl A., Brock N. \& Schneider B. 1973. Studies on the pharmacokinetics of cyclophosphamide in sheep. Arzneimittelforschung 23(4):491-500.

Silva M.M. 2000. Efeito da verminose na resposta imune humoral em caprinos. Dissertação (Mestrado em Medicina Veterinária), Instituto de Ciências da Saúde, Universidade Paulista.

Tarayre J.P., Barbara M., Aliaga M. \& Tisne-Versailles ]. 1990. Comparative actions of immunosuppressants, glucocorticoids and non-steroidal antiinflammatory drugs on various models of delayed hypersensitivity and a non-immune inflammation in mice. Arzneimittelforschung 40(10):11251131.

Yegana Y., Hod I., Livneh O. \& Herz A. 1983. Changing pattern of the serum proteins in asymptomatic sheep treated with cyclophosphamide for chemical shearing. Brit. Vet. J. 139:415-422.

Zar J.H. 1996. Biostatistical Analysis. 3rd ed. Practice Hall, New Jersey. $662 p$. 